\title{
JOURNAL OF APPLIED PROBABILITY VOLUME 50 (2013): INDEX
}

Abraham, R. and Delmas, J. -F. A construction of a $\beta$-coalescent via the pruning of binary trees

Agarwal, A., Dey, S. And Juneja, S. Efficient simulation of large deviation events for sums of

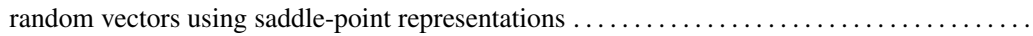

Aletti, G., Ghiglietti, A. And Paganoni, A. M. Randomly reinforced urn designs with

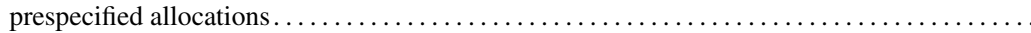

Aristoff, D. AND Radin, C. Emergent structures in large networks $\ldots \ldots \ldots \ldots \ldots \ldots \ldots \ldots \ldots$

Athreya, K. B. AND Hong, J. -I. An application of the coalescence theory to branching random

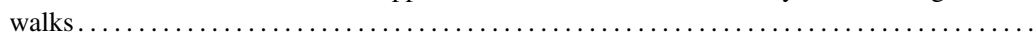

Avratchenkov, K. E., Piunovskiy, A. And Zhang, Y. Markov processes with restart ..........

BALL, F. AND SIRL, D. Acquaintance vaccination in an epidemic on a random graph with specified

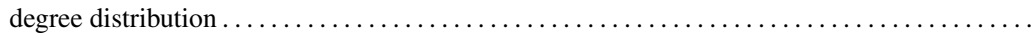

Bar-Lev, S. K., Schulte-Geers, E. and Stadje, W. Conditional limit theorems for the terms of a

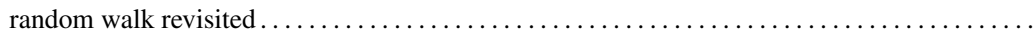

BäUERLE, N. AND LI, Z. Optimal portfolios for financial markets with Wishart volatility ........ .

Baumann, H. AND SAndmann, W. Computing stationary expectations in level-dependent QBD

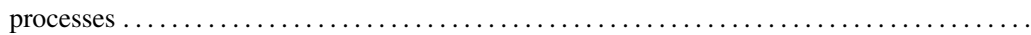

Bertoin, J. Almost giant clusters for percolation on large trees with logarithmic heights ........

— On largest offspring in a critical branching process with finite variance $\ldots \ldots \ldots \ldots \ldots \ldots$.

Blanghaps, N., Nov, Y. and Weiss, G. Sojourn time estimation in an M/G/ $\infty$ queue with partial

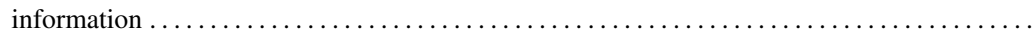

Blath, J., Casanova, A. G., Kurt, N. and Spano, D. The ancestral process of long-range seed bank models

PAGES

$772-790$

$703-720$

486-498

883-888

893-899

960-968

1147-1168

871-882

1025-1043

151-165

603-611

791-800

1044-1056

$741-759$

909-917

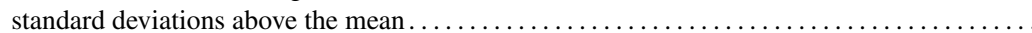

Boxma, O. J. see Fralix, B. H. and Kella, O.

Breuer, L. The resolvent and expected local times for Markov-modulated Brownian motion with

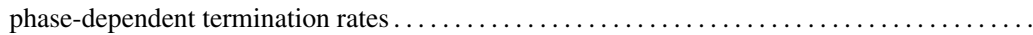

Burkschat, M. AND Navarro, J. Dynamic signatures of coherent systems based on sequential order

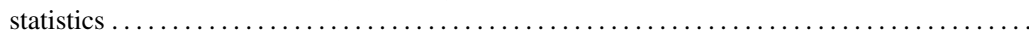

Casanova, A. G. see Blath, J.

Castro, I. T. see Mercier, S.

$\mathrm{CHA}$, J. H. On stochastic predictions of failure processes under population heterogeneity ........

Che, X. And Dassios, A. Stochastic boundary crossing probabilities for the Brownian motion ....

Chen, F. And Hall Frs, P. Inference for a nonstationary self-exciting point process with an application in ultra-high frequency financial data modeling

Chen, G. -Y. And SAloff-Coste, L. Comparison of cutoffs between lazy walks and Markovian

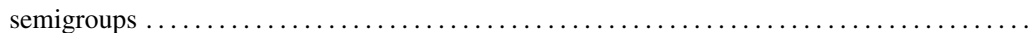

Chen, M. -R. And Kuba, M. On generalized Pólya urn models . . . . . . . . . . . . . . . .

Chronopoulou, A. and Fellouris, G. Optimal sequential change detection for fractional diffusion-

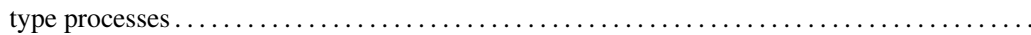

Connor, S. Optimal coadapted coupling for a random walk on the hyper-complete graph .......

DAssios, A. AND ZHAO, H. A risk model with delayed claims $\ldots \ldots \ldots \ldots \ldots \ldots \ldots \ldots \ldots \ldots$ see $\mathrm{CHE}, \mathrm{X}$.

Debicki, K., Sierpinska, I. And Zwart, B. Asymptotics of hybrid fluid queues with Lévy input..

Delmas, J. -F. see Abraham, R. 
Denisov, D. And Shneer, V. Asymptotics for the first passage times of Lévy processes and random

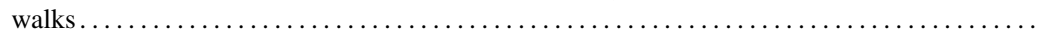

Dey, S. see Agarwal, A.

Di Crescenzo, A., Iuliano, A., Martinucci, B. And Zacks, S. Generalized telegraph process

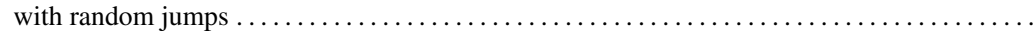

—, Frostig, E. And Pellerey, F. Stochastic comparisons of symmetric supermodular functions

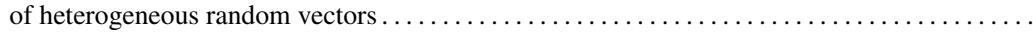

$450-463$

$464-474$

Du, K. And Neufeld, A. D. A note on asymptotic exponential arbitrage with exponentially decaying failure probability...

801-809

374-387

Fellouris, G. see Chronopoulou, A.

FENG, Q. AND Hu, Z. Phase changes in the topological indices of scale-free trees ............

Feng, X., Zhang, S. ANd Li, X. A note on the mixture representation of the conditional residual

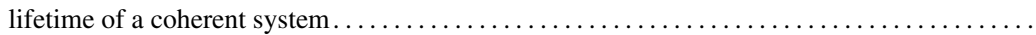

Ferré, D., Hervé, L. ANd Ledoux, J. Regular perturbation of $V$-geometrically ergodic Markov chains ...

$516-532$

$475-485$

$184-194$

FINK, H. Conditional characteristic functions of Molchan-Golosov fractional Lévy processes with

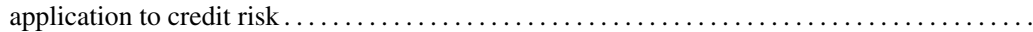

- , KlÜPPElberg, C. And Zähle, M. Conditional distributions of processes related to fractional Brownian motion .

983-1005

$166-183$

Fralix, B. H., Van Leeuwaarden, J. S. H. and Boxma, O. J. Factorization identities for reflected processes, with applications

$632-653$

Frostig, E. see Di Crescenzo, A.

Fu, J. C. see Wu, T. -L.

FUJII, T. Nonparametric estimation for a class of piecewise-deterministic Markov processes ......

Garner, W. AND Politis, D. N. The correct asymptotic variance for the sample mean of a

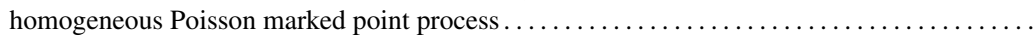

Ghiglietti, A. see Aletti, G.

Glaz, J. see Wu, T. -L.

Glynn, P. W. see PihlsgaArd, M.

Goldstein, L. And Reinert, G. Stein's method for the beta distribution and the Pólya-Eggenberger

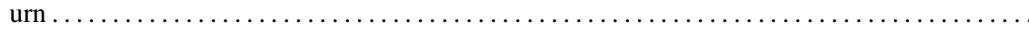

GRÜBel, R. And Hitczenko, P. Pruned discrete random samples $\ldots \ldots \ldots \ldots \ldots \ldots \ldots \ldots \ldots$

Guerry, M. -A. On the embedding problem for discrete-time Markov chains . ..............

Gupta, N. Stochastic comparisons of residual lifetimes and inactivity times of coherent systems..

Hall Frs, P. see Chen, F.

HANSEN, J. AND JAWORSKI, J. Predecessors and successors in random mappings with exchangeable

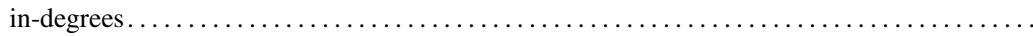

Hervé, L. ANd Ledoux, J. Geometric $\rho$-mixing property of the interarrival times of a stationary

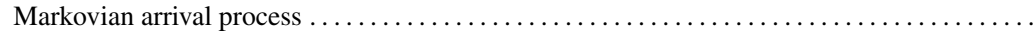
see FerRÉ, D.

Hitczenko, P. see GrüBel, R.

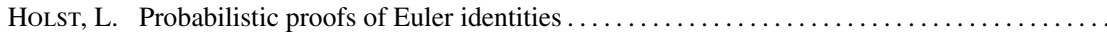

Hong, J. -I. Coalescence on subcritical Bellman-Harris age-dependent branching processes ...... see Athreya, K. B.

Hook, J. Critical path statistics of max-plus linear systems with Gaussian noise .

$1187-1206$

$542-556$

918-930

$848-860$

$721-740$

$598-601$

$1206-1211$

$576-591$

$654-670$

$592-597$

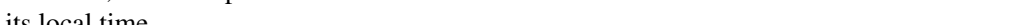

Hu, Z. AND JIANG, B. On joint ruin probabilities of a two-dimensional risk model with constant

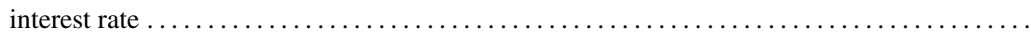

$309-322$

- see FENG, Q.

Iuliano, A. see Di Crescenzo, A.

JAWORSKI, J. See HANSEN, J.

Jelenković, P. R. and Olvera-Cravioto, M. Convergence rates in the implicit renewal theorem

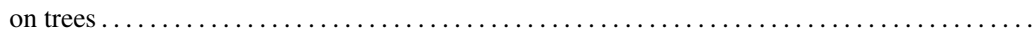


Jiang, B., Tan, J., Wei, W., Shroff, N. B. And Towsley, D. Heavy tails in queueing systems:

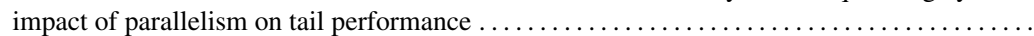
see $\mathrm{Hu}, \mathrm{Z}$.

JIANG, Y. AND XU, W. On the number of turns in reduced random lattice paths ...

Juneja, S. see Agarwal, A.

Kella, O. and Stadje, W. Asymptotic expected number of passages of a random walk through an interval

AND Boxma, O. J. Useful martingales for stochastic storage processes with Lévy-type input .

KLÜPPELbERG, C. see FInK, H.

KrIEger, A. M. ANd SAMuel-CAHn, E. Generalized bomber and fighter problems: offline optimal

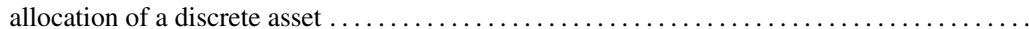

KubA, M. see CHEN, M. -R.

KUGLER, J. AND WACHTEL, V. Upper bounds for the maximum of a random walk with negative drift

KURT, N. see BLATH, J.

Lambert, A. And Trapman, P. Splitting trees stopped when the first clock rings and Vervaat's

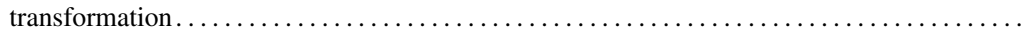

LeCKey, K. AND Neininger, R. Asymptotic analysis of Hoppe trees $\ldots \ldots \ldots \ldots \ldots \ldots \ldots \ldots \ldots$

Ledoux, J. see Ferré, D. and Hervé, L.

LEE, C. see Hu, Y.

LeE, Y. AND Rheinlander, T. The minimal entropy martingale measure for exponential Markov

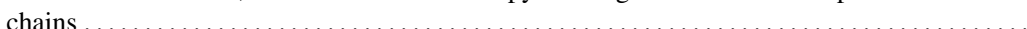

LEFÈVRe, C. AND LOISEL, S. On multiply monotone distributions, continuous or discrete, with

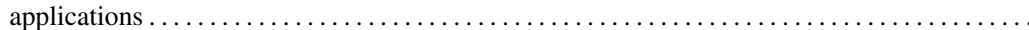

LI, B., TANG, Q. AND Zhou, X. A time-homogeneous diffusion model with tax ..............

LI, X. see FENG, X.

LI, Z. see BÄUERLE, N.

Liao, X., Peng, Z. and Nadarajah, S. Tail properties and asymptotic expansions for the maximum

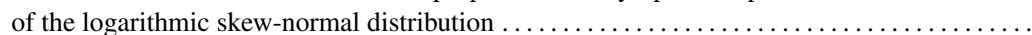

LiNDBERG, C. see EKSTRÖM, E.

LOISEL, S. See LEFÈvRE, C.

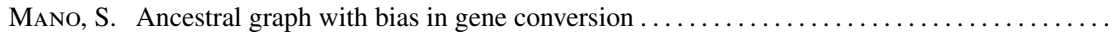

Duality between the two-locus Wright-Fisher diffusion model and the ancestral process with recombination...

439-449

$403-418$

$1131-1146$

208-227

$228-238$

$344-358$

$827-847$

195-207

900-907

Martinucci, B. see Di Crescenzo, A.

MARTY, R. From Hermite polynomials to multifractional processes . . . . . . . . . . . . . . . . .

Matsumoto, K. and NaKata, T. Limit theorems for a generalized Feller game

$323-343$

$54-63$

Mercier, S. ANd CAStro, I. T. On the modelling of imperfect repairs for a continuously monitored

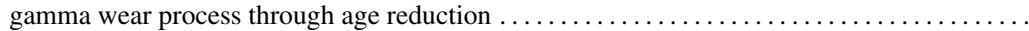

Metzler, A. The Laplace transform of hitting times of integrated geometric Brownian motion ...

Miao, D. W. -C. Analysis of the discrete Ornstein-Uhlenbeck process caused by the tick size effect

Mikosch, T., SAMorodnitsky, G. AND TAFAKori, L. Fractional moments of solutions to stochastic

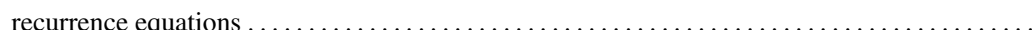

Nadarajah, S. see LiaO, X.

NaKata, T. see Matsumoto, K.

NaVARro, J. see Burkschat, M.

NeININGER, R. see LECKEy, K.

Neufeld, A. D. see Du, K.

Nov, Y. see Blanghaps, N.

Olvera-Cravioto, M. see Jelenkovic, P. R.

Paganoni, A. M. see Aletti, G.

Patie, P. Asian options under one-sided Lévy models $\ldots \ldots \ldots \ldots \ldots \ldots \ldots \ldots \ldots \ldots \ldots \ldots$

Pellerey, F. see Di Crescenzo, A.

Peng, Z. see LiaO, X.

Perry, D., Stadje, W. AND Zacks, S. A duality approach to queues with service restrictions and

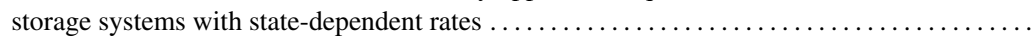

PihlsgaARD, M. AND GLYNn, P. W. On the dynamics of semimartingales with two reflecting barriers Piunovskiy, A. see Avratchenkov, K. E.

$1057-1076$

$1102-1116$

969-982 
Politis, D. N. see GARner, W.

Puccetti, G. And Rüschendorf, L. Sharp bounds for sums of dependent risks..............

RADin, C. see ARISTOFF, D.

Raschel, K. see VAN LeeuwaARden, J. S. H.

REeD, J., WARD, A. R. AND ZHAN, D. On the generalized drift Skorokhod problem in one dimension

REINERT, G. see Goldstein, L.

Rheinlander, T. see LeE, Y.

Rüschendorf, L. see Puccetti, G.

SALEZ, J. Joint distribution of distances in large random regular networks.

SAloff-Coste, L. see Chen, G. -Y.

Samorodnitsky, G. see Mikosch, T.

Samuel-Cahn, E. see Krieger, A. M.

Sandmann, W. see Baumann, $\mathrm{H}$.

Schulte-Geers, E. see Bar-Lev, S. K.

Shapiro, A. Consistency of sample estimates of risk averse stochastic programs .............

Sherlock, C. Optimal scaling of the random walk Metropolis: general criteria for the 0.234 acceptance rule.

ShNeER, V. see Denisov, D.

SHroff, N. B. see JiAnG, B.

Sierpinska, I. see DeBICKI, K.

SIRL, D. see BALL, F.

Spano, D. see Blath, J.

Stadje, W. see Perry, D., Kella, O. and Bar-Lev, S. K.

TAFAKORI, L. see MiKosch, T.

TAN, J. see JIANG, B.

TANG, Q. see LI, B.

Tehranchi, M. R. On the uniqueness of martingales with certain prescribed marginals .........

Towsley, D. see JiAng, B.

Trapman, P. see LAMBERT, A.

VAN LeEuWAarden, J. S. H. And Raschel, K. Random walks reaching against all odds the other

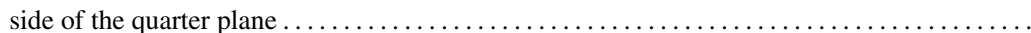
see Fralix, B. H.

WaChTEl, V. see Kugler, J.

WARD, A. R. see REED, J.

WEI, W. see JIANG, B.

Weiss, G. see Blanghaps, N.

Wu, T. -L., Glaz, J. AND Fu, J. C. Discrete, continuous and conditional multiple window scan statistics

Wu, X. AND ZHOU, X. Open bandit processes with uncountable states and time-backward effects .

$\mathrm{XU}, \mathrm{W}$. see JIANG, Y.

YAO, Y. -C. A duality relation between the workload and attained waiting time in FCFS G/G/s

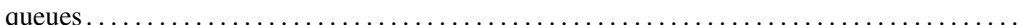

Zacks, S. see Perry, D. and Di Crescenzo, A.

ZÄHLE, M. see FINK, H.

ZHAN, D. see REED, J.

ZHANG, H. AND ZHU, Y. Domain of attraction of the quasistationary distribution for birth-and-death processes

Zhang, S. see FENG, X.

Zhang, Y. see Avratchenkov, K. E.

Zhao, H. see Dassios, A.

ZHou, X. see $\mathrm{Wu}, \mathrm{X}$. and $\mathrm{LI}, \mathrm{B}$.

ZHU, L. Central limit theorem for nonlinear Hawkes processes $\ldots \ldots \ldots \ldots \ldots \ldots \ldots \ldots \ldots$

ZHU, Y. see ZHANG, H.

ZWART, B. see DEBICKI, K. 